\title{
TRANSITIVITY SYSTEM ON DONALD TRUMP'S SPEECH ON ISIS
}

\author{
M. Asril Marpaung ${ }^{1}$, Amrin Saragih ${ }^{2}$, Anni Holila Pulungan ${ }^{3}$ \\ Postgraduate School, State University of Medan \\ Jl. Willem Iskandar Pasar V Medan Estate-Medan-Indonesia \\ m.asrilmarpaung@gmail.com ${ }^{l}$,amrin_saragih@yahoo.com ${ }^{2}$, \\ anniholilapulungan@gmail.com ${ }^{3}$
}

\begin{abstract}
The study aims to find out (1) the transitivity processes used by Donald Trump in his speech on ISIS for his political campaign rally, and (2) the most dominant processes used Donald Trump in his speech on ISIS for his political campaign rally. The source of data for this study is a speech about ISIS delivered by Donald Trump at Youngstown State University, in Youngstown, Ohio, August 15th, 2016. The data of this study are the clauses found in the speech. The instrument of this study was the the researcher himself. The data were analyzed based on Halliday's Systemic Functional Linguistics, specifically Transitivity System. This research belongs to qualitative research. The findings of the study shows that there are six common processes found in the speech, namely $43.8 \%$ of material processes, $32.3 \%$ of relational process which consists of $25.6 \% 25.6 \%$ attributive relational processes and 6.7 $\%$ of identifying relational process, $11.2 \%$ of verbal process, $10.3 \%$ of mental process, $1.5 \%$ of existential processes, and $0.9 \%$ of behavioral processes; as for participants, the researcher has found $21.3 \%$ of actors, $19.5 \%$ of goal , $12 \%$ of carrier, $12 \%$ of attribute, and the rest participant roles are less than $30 \%$.
\end{abstract}

Keywords: Critical Discourse Analysis (CDA), Transitivity System, Speech

\section{INTRODUCTION}

Discourse can be described as language beyond the sentence (Schiffrin, Tannen, and Hamilton, 2001:1). While language has a primary function as a tool that helps people to communicate with each other. The purpose of communication is not only to deliver ideas, but sometimes it also aims to represent any social practices in a society.

Discourse can be in written or spoken form. The example of discourse in spoken form can be seen in a speech. There are many kinds of speech, one of them is persuasive speech. This kind of speech is often used by someone to a group of people in order to influence or change their choices, thoughts, and responses toward ideas, issues, concepts, or products.

Discourse can be used to assert power, knowledge, or manipulation. On the contrary, discourse can also be used for resistance, critique, and defense against manipulation. The occasion in which discourse is used to assert, legitimate, and sustain power is a campaign speech. A campaign speech is a powerful tool utilized by politicians to express their view, ideas, and feelings to public with the sole purpose of influencing them. The electorate's mind might be "rewritten" as the politcial discourse containing certain ideology re-shape and re-direct them, perhaps, without their realizing. This will lead them to agree with the speaker's opinion. This is thanks to the effective language use. With his language, the politician promotes his programs and present themselves as the best candidate for people's favor. It is undeniable that politics is a struggle for power to put certain political ideas into practice. In its process, language plays a crucial role. This is because every political action is prepared, implemented, and played by language.

One of the ways to analyze discourse is by using Transitivity System which is part of Systemic Functional Analysis proposed by Halliday (1994). Transitivity System realizes the experiential function of language (clause). This is one of the three strands of meaning in Systemic Functional Linguistics, which are called metafunctions of language (Gerot and Wignell, 1994:12-14).. Those three strands of meaning are (1) ideational meaning, which consists of experiential meaning and logical meaning, (2) interpersonal meaning, and (3) textual meaning. 
Experiential meaning is the meaning about phenomena - about things (living and non living, abstract and concrete), about goings on (what the things are or do) and the circumstances surrounding these happenings and doings. This experiential meaning is realized through Transitivity System.

Halliday (1994) asserted that there are three elements in transitivity to represent the real world phenomena in linguistic structure. They are process, participants, and circumstance. Process consists of six types, namely Material Process, Mental Process, Relational Process, Behavioral Process, Verbal Process, and Existential Process. As for the participants, there are also many types, which are inherent to the process. Actor, Goal, Client and Recipient are participants for material process. Senser and Phenomenon are participants for mental process. Carrier, Attribute, Token, and Value are participants for relational process. Behaver is participant for behavioral process. Sayer, Verbiage, Receiver, and Target are participants for verbal process. Finally, Existent is participant for existential proces.

\section{PURPOSE OF THE STUDY}

The study aims to find out (1) the transitivity processes used by Donald Trump in his speech on ISIS for his political campaign rally, and (2) the most dominant processes used Donald Trump in his speech on ISIS for his political campaign rally. The source of data for this study is a speech about ISIS delivered by Donald Trump at Youngstown State University, in Youngstown, Ohio, August 15th, 2016. The data of this study are the clauses found in the speech. This speech was analyzed because it talked about ISIS. It is interesting to study because Donald Trump made a controversial decision in which he banned muslims to enter America. This decision is the solution proposed by him to protect his country and stop terrorism occuring again in America.

\section{RESEARCH METHOD}

This study was conducted by applying qualitative descriptive design. Qualitative descriptive design means that the data collected is in the form of words rather than numbers (Bogdan and Biklen: 1992). The document to be analyzed in this research are in the form of text which was transcribed from the video of speech on ISIS by the US elected president Donald Trump. The data of this study are the clauses found in Donald Trump's speech at Youngstown State University, in Youngstown, Ohio, August 15th, 2016. The topic of the speech is about ISIS/ Radical Islam Terrorism. There are 652 clauses. And the source of the data is the speech about ISIS delivered by Donald Trump which was delivered at Youngstown State University, in Youngstown, Ohio, August 15th, 2016. The reasons for taking this speech as the source of data is that they contain Donald Trump's talk on ISIS.

To collect the data, the researcher acts as the instrument of data collection. The steps of collecting the data are: (1) Searching and downloading the video of Donald Trump's speeches on ISIS in internet (Youtube); (2) Searching the transcripts for each of the videos of Donald Trump's speeches on ISIS. This is done to make analysis easier; (3) Watching the video of Donald Trump's speeches on ISIS. This isdone to understand his talk in the speech; (4) Comparing the transcripts and the videos. This is done to match the content of the transcripts with the videos; (5) Marking notes on all of the utterances which mention, refer, or imply ISIS in the trancripts; (6) Taking all of the utterances which mention, refer, or imply ISIS in the trancripts.

To analyze the data, the researcher used Sytemic Functional Linguistic which only focuses the experiential meaning on grammatical feature which is based on the transitivity system. Although there are three elements of Transitivity System (process, participants, and circumstance), the researcher only analyzed processes and participants.

\section{FINDINGS AND DISCUSSIONS}

\section{Transitivity Analysis of Donald Trump's speech}

After segmenting the utterances in the Donald Trump's speech, the researcher counted the total clauses in the speech. From the analysis it was found that Donald Trump's speech on ISIS consists of 652 clauses. Specifically the total clauses consist of 491 ranking clauses and 161 embedded clauses.

Types of Process found in Donald Trump's Speech.

Below are the details of types of processes and participants found in the speech. 


\begin{tabular}{clcc}
\hline No. & Types of Process & Number & Percentage \\
\hline 1 & Material & 286 & 43.8 \\
2 & Relational & & \\
& a. Attributive & 167 & 25.6 \\
& b. Identifying & 44 & 6.7 \\
3 & Verbal & 73 & 11.2 \\
4 & Mental & 67 & 10.3 \\
5 & Existential & 10 & 1.5 \\
6 & Behavioral & 6 & 0.9 \\
\hline
\end{tabular}

Table 1 The occurence of processes in Donald Trump's speech on ISIS

Table 1 shows the types of process which are categorized into six types. They are material, mental, relational, verbal, behavioral, and existential processes. It can be seen that material process is the most dominant process found in the data analysis. The researcher found 286 occurences of material processes or about $43,8 \%$. This implies that, by using material clauses, Donald Trump construes the representation of his world through more in terms of action, which revolve around what ISIS did to the world, what the previous administration did so ISIS rose. Trump also used material clause to show what action he will do to fight ISIS when he becomes the US president. The second processes mostly found are relational processes. Relational processes are divided into two subcategories, which are attributive and identifying. The researcher found 167 occurences of attributive relational processes or about 25.6 $\%$ and 44 identifying relational clauses or about $6.7 \%$. Donald Trump used relational processes to mainly describe the situation caused by ISIS and situation before the wrong policy of the previous administration regarding ISIS-handling. . He also used relational processes todescribe ISIS. The third processes mostly found are verbal processes. There are 73 occurences or about $11.2 \%$, which are used to show former president Obama's statements regarding terrorism and its handling. Further, he also used verbal process to show his position towards ISIS handling. In addition, through verbal processes, he shows his power when he becomes the president later by speaking out against terrorism. Next, the researcher found 67 occurences or about $10.3 \%$ of mental processes. Trump used mental processes to bring his audience to remember brutalitiy ISIS has done and the wrong steps the Obama-Clinton has taken as the defense policy. He also used mental processes to show his opinion about the criteria people who are allowed to enter US.There are also 10 existential processes or about $1.5 \%$. They are used to emphasize that the the ISIS attack exists and to show that there is consequence for the people who support ISIS. The least found is behavioral process. There are 6 occurences or about $0.9 \%$ of behavioral processes which are used to show physiological action of various people towards ISIS.

\section{Material Processes}

Material process is a process of doing and happening (Halliday: 1994). There are two participants involved in the material process. The main participant is an Actor that is the one that does the deed or brings about the change. In addition, there may also be a Goal that is a participant impacted by a doing or in which the one done to/with. Here are the examples of material processes:

\section{Excerpt 1; Clause 4}

\begin{tabular}{|l|l|l|l|}
\hline In the $20^{\text {th }}$ Century & $\begin{array}{l}\text { the United } \\
\text { States }\end{array}$ & defeated & $\begin{array}{l}\text { Fascism, Nazism, and } \\
\text { Communism }\end{array}$ \\
\hline circ: loc: time & actor & pr: material & goal \\
\hline
\end{tabular}

The above clause contains a material process. It is indicated by the action verb defeated which shows a process of doing. The actor is the United States which might can refer to the United States' government and people. United States acts as the actor because it is the one who does the action 'defeated'. There is also a goal, that is Fascism, Nazism, and Communism which is impacted by the action 'defeated'. The clause describes a history of America in which there was a time in the past that America faced threats which were Fascism, Nazism, and Communism and successfully defeated them. 


\section{Excerpt 2; Clause 7a}

\begin{tabular}{|l|l|l|l|}
\hline (an ISIS attack) & (was) launched & $\begin{array}{l}\text { outside the war zones of the } \\
\text { Middle East }\end{array}$ & every 84 hours. \\
\hline [goal] & pr: material & circ: loc: place & circ: ext: Freq \\
\hline
\end{tabular}

This passive clause is an adjective clause taken from the complete clause 'This summer, there has been a ISIS attack launched outside the war zones of the Middle East, hard to believe, every 84 hours. The above clause contains material process. It is indicated by the action verb launchedwhich shows a process of doing. An ISIS attack is the goal because to it the action launched is done. As for the actor, it is implicitly mentioned. We can tell from the word ISIS attack that the one who did the attack was ISIS. Thus, we can conclude the actor is ISIS. The clause describes that ISIS launched an attack not only limited to the war zones in Middle East countries, but also outside Middle East as mentioned afterwards like the United States, French, Germany, etc.

\section{Relational Process}

Relational process involves states of being and having (Halliday: 1994). Relational process can be classified according to whether it is being used to identify something or to assign quality to something. The process which establishes an identity is called Identifying Process while process which assign a quality is called Attributive Process. Each has its own characteristic participant roles. In Identifying process, there are token and value. In Attributive Process, there are carrier and attribute. Each of the two relational processes can be further sub-classified according to whether they are: intensive, possessive and circumstantial. Thus, we have six types of relational processes; Attributive- intensive, Attributive-possessive, Attributive-circumstantial, Identifying-intensive, Identifying-possessive, and Identifying-circumstantial. Here is the example of relational processes found in the speech:

\section{Excerpt 3; Clause 16}

\begin{tabular}{|l|l|l|}
\hline another 22 & were & gravely injured. \\
\hline Carrier & Pr: relational: attrib: intens & Attribute \\
\hline
\end{tabular}

The above clause contains attributive relational process which is indicated by the verb were. This shows a process of being. As this process assignsa quality of another 22 innocent Americans as gravely injured, it is also labelled as intensive. The carrier is another 22, which refers to the 22 innocent Americans who became the victims of ISIS attack, because it is the entity which has a quality ascribed to it. The Attribute is gravely injured because it is the quality ascribed to the carrier (another 22). This clause describes that 22 more Americans who have nothing to do with ISIS became the victim of ISIS terror and were gravely injured. This is the addition of the killing victim of ISIS as many as 14 people at an office party in San Bernardino. Thus, there are 36 victims in San Bernardino attack; 14 killed and 22 gravely injured.

\section{Verbal Process}

Verbal process is process of saying (Halliday, 1994). This includes symbolic signalling. A verbal process has four inherent participants, namely: sayer, receiver, verbiage, and target. Sayer is the one responsible for the verbal process or signal source. It is typically a human, but sometimes it can be nonhuman which is capable of putting out signal. Receiver is the one to whom verbal process (saying) is addressed. It is typically a human. Verbiage is the message/ content of what is said. It can be the topic of what is said or can be the name of the saying. Target is the one at which the verbal process (saying) is directed. It acts verbally on another entitiy. It is does not have to be human. It only appears for some limited verbs which usually indicated saying good or bad things about someone or something (such as, praise, accuse, and so on). See the example of verbal processes found in the speech as follows:

\section{Excerpt 4; Clause 124}

\begin{tabular}{|l|l|l|}
\hline He & pledged & $\begin{array}{l}\text { that we no longer be a "senior partner," that "sought to dictate } \\
\text { our terms." }\end{array}$ \\
\hline Sayer & $\begin{array}{l}\text { Pr: } \\
\text { Verbal }\end{array}$ & Projected \\
\hline
\end{tabular}


The above clause contains verbal process which is indicated by the verb pledged. This shows a process of saying. The sayer is he which refers to Obama. We can trace this back to the clause no. 120 (In a series of speeches, President Obama described America as 'arrogant', 'dismissive', 'derisive' and a 'colonial power'.) The sayer is Obama who because this entity is the one responsible for doing the verbal process pledged. This clause has no verbiage but the process pledged projects a clause no. 125 which is that we would no longer be a "senior partner," that "sought to dictate our terms." However this clause is not included in verbal process analysis but analysed separately to another clause. This clause describes how Trump criticized Obama for putting bad image on America. This is the elaboration of the previous clause that says America is arrogant, dismissive, derisive, and a colonial power in Obama's perspective.

\section{Mental Process}

Mental process is process of sensing: feeling, thinking, perceiving. Some processes involve not material action but phenomena described as states of mind or psychological event. People are not always talking about concrete process if doing. They very often talk not about what they are doing, but about what they think or feel (Halliday: 1994). The participant role of mental process are senser and phenomenon. Senser is the the conscious human being or anthropomorphized non-human who perform mental process: feel, think, or perceive. The phenomenon is that which is sensed: felt, thought or perceived by the conscious sense. The following are the examples of mental processes found in the speech:

\section{Excerpt 5; Clause 8}

\begin{tabular}{|c|l|c|c|}
\hline Here, in America & we & have seen & one brutal attack after another \\
\hline Circ: loc: place & Senser & Pr: mental & Phenomenon \\
\hline
\end{tabular}

The above clause contains mental process which is indicated by the verb seen. This shows a process of perception. The senser is we, which refers to Trump and his audience, because this entity is conscious human beings who perceive. The phenomenon is one brutal attack after another because this entity is what is perceived by the senser (Trump and his audience). In this clause, Trump tried to bring his audience memory to remember how brutal ISIS was. Continuous attacks were launched in America, which have claimed many victims.

\section{Existential Process}

Existential process is process of existence (Halliday: 1994). It represents that something exists or happens. The existential clause involves the use of the word there. "There" has no representational function and left unanalyzed. Existential process typically employ the verb "be" or synonyms such as exist, arise, occur the only obligatory participant in an existential process is called the existent. The researcher has found existential process in the speech, such as:

\section{Excerpt 6; Clause 7}

\begin{tabular}{|l|l|l|l|}
\hline This summer, & there & has been & $\begin{array}{l}\text { an ISIS attack launched outside the war } \\
\text { zones of the Middle East, hard to believe, } \\
\text { every 84 hours. }\end{array}$ \\
\hline Circ: loc: time & & Existential & Existent \\
\hline
\end{tabular}

The above clause contains existential process which is indicated by the word ther and the copula verb been. It shows the process of existence. The existent is labelled to the entity an ISIS attack launched outside the war zones of the Middle East, hard to believe, every 84 hours. This clause describes that Trump informed his audience that an ISIS attack existed and happened outside the war zones of Middle East for every 84 hours.

\section{Behavioral Process}

Behavioral process is process of physiological and psychological behavioral, like breathing, dreaming, snoring, smiling, hiccupping, looking, listening, watching, and pondering (Halliday: 1994). He describes the process semantically as a "half way hour" between mental and material process. It means that the meanings they realized are midway between materials on the one hand and mentals on the 
other. They are in part about action that has to be experienced by conscious being. There is one obligatory participant: the behaver, and is typically a conscious being (like a senser in the mental process clause). But, the process is one of doing, not sensing. The following are examples of behavioral process found in the speech.

\section{Excerpt 7; Clause 33}

\begin{tabular}{|l|l|l|}
\hline France & is suffering & gravely, \\
\hline Behaver & Pr: behavioural & Circ: manner \\
\hline
\end{tabular}

The above clause contains behavioral process which is indicated by the verb suffering. This shows process of physiology. The behaver is France, which refers to French people. It is because the entity French people is the one who. This clause describes thatISIS for Trump, ISIS has spread terror not only in middle east and america, but also other nation in this case France. ISIS terrorized France, so French people are suffering very much.

As this research focused on Trump and ISIS, so to get more accurate picture of ISIS by Donald Trump, the researcher felt the need to see the participants focusing on Donald Trump and ISIS. In the speech, Donald Trump was referred as 'I, we, and my administration'. While ISIS was referred as terrorist, Islamic terrorists, ISIS, and enemy.

\begin{tabular}{clcc}
\hline No. & Types of Participants & Number & Percentage \\
\hline 1 & Actor & 74 & 47.5 \\
2 & Senser & 15 & 9.6 \\
3 & Carrier & 15 & 9.6 \\
4 & Token & 1 & 0.6 \\
5 & Possesor & 8 & 5.1 \\
6 & Sayer & 30 & 19.3 \\
7 & Behaver & 0 & 0 \\
8 & Existent & 0 & 0 \\
9 & Goal & 2 & 1.3 \\
10 & Phenomenon & 1 & 0.6 \\
11 & Attribute & 0 & 0 \\
12 & Value & 0 & 0 \\
13 & Possessed & 0 & 0 \\
14 & Verbiage & 1 & 0.6 \\
15 & Client & 0 & 0 \\
16 & Recipient & 0 & 0 \\
17 & Initiator & 4 & 2.6 \\
18 & Range & 0 & 0 \\
19 & Behavior & 0 & 0 \\
20 & Inducer & 0 & 0 \\
21 & Attributor & 4 & 2.6 \\
22 & Assigner & 1 & 0.6 \\
23 & Receiver & 0 & 0 \\
24 & Target & 0 & 00 \\
\hline & Total & 156 & \\
\hline & & Table 2 The occurences of Donald & Trump as participants \\
\hline
\end{tabular}

Table 2 shows the mentioning of Donald Trump as participants. Donald Trump referred himsefl in the speech with various choice of words, namely I, we, and my administration. The participant roles labelled to Donald Trump found are actor, senser, carrier, token, possessor, sayer, goal, phenomenon, verbiage, initiator, attributor, and assigner. The dominant participant role labelled to Donald Trump is actor with 74 occurences or about $47.5 \%$. This shows that Donald Trump described himself as the one who is actively doing actions related to ISIS. This is followed by sayer with 30 occurences or about $19.3 \%$. While the rest participants, such as senser, carrier, token, possessor, goal, phenomenon, verbiage, initiator, attributor, and assigner didn't give significant effect with the occurences which are less than $10 \%$ for each. While for the other participant roles, which referred to Donald Trump himself, 
such as, behaver, existent, attribute, value, possessed, client, recipient, range, behavior, inducer, receiver and target are not found in the speech.

\begin{tabular}{clcc}
\hline No. & Types of Participants & Number & Percentage \\
\hline 1 & Actor & 25 & 65.8 \\
2 & Senser & 0 & 0 \\
3 & Carrier & 3 & 7.9 \\
4 & Token & 0 & 0 \\
5 & Possesor & 0 & 0 \\
6 & Sayer & 1 & 2.6 \\
7 & Behaver & 0 & 0 \\
8 & Existent & 0 & 0 \\
9 & Goal & 6 & 15.9 \\
10 & Phenomenon & 0 & 0 \\
11 & Attribute & 0 & 0 \\
12 & Value & 1 & 2.6 \\
13 & Possessed & 0 & 0 \\
14 & Verbiage & 0 & 0 \\
15 & Client & 0 & 0 \\
16 & Recipient & 0 & 0 \\
17 & Initiator & 0 & 0 \\
18 & Range & 0 & 0 \\
19 & Behavior & 0 & 0 \\
20 & Induce & 0 & 0 \\
21 & Attributor & 1 & 2.6 \\
22 & Assigner & 1 & 2.6 \\
23 & Receiver & 0 & 0 \\
24 & Target & 0 & 0 \\
\hline & Total & 38 & \\
\hline & & Table 3 The occurence of ISIS $a s$ Participants & \\
\hline
\end{tabular}

Table 3 shows the occurences of ISIS as participants. In the speech, Donald Trump referred ISIS as ISIS, Islamic terrorists, and enemy. The researcher found that participant roles which are labelled to ISIS are actor, carrier, sayer, goal, value, attributor, and assigner. The most dominant participant label for ISIS is actor with 25 occurences or about $65.8 \%$. This shows that Donald Trump described ISIS actively doing act terrorism. The secondly most dominant participant label for ISIS is goal with 6 occurences or about $15.6 \%$. This shows that Donald Trump described ISIS as the target of extermination. The remaining participants, such as carrier, sayer, value, attributor, and assigner are not significant enough to give some effect with the occurence number which is under 4 or not more than $7.9 \%$ for each. While participant roles, such as senser, token, possessor, behaver, existent, phenomenon, attribute, possessed, verbiage, client, recipient, initiator, range, behavior, inducer, attributor, assigner, receiver, and target are not found in the text. This is because the inherent procesess are also not found in the speech.

Based on data of the transitivity found in the speech, it is concluded that from Donald Trump's point of view, through material process which was dominantly found, ISIS is the one responsible for actively doing brutal terrors around the world and Donald Trump himself is the most suitable candidate president for the United States, as he described himself, through material process which was dominantly found, as someone with power who will obviously eliminate ISIS with his future programs in his future administration. In addition, with quite significant number of verbal processes, Donald Trump, also shows his power to persuade other nations to work together with him to eliminate ISIS. 


\section{CONCLUSIONS AND SUGGESTIONS}

After doing the research, the researcher concludes:

(1) The researcher found that there are six processes occuring in Donald Trump's speech on ISIS which was delivered at Youngstown State University, in Youngstown, Ohio, August 15th, 2016 during his political campaing rally for the US president. The processes are material process, mental processes, relational proceses, verbal processes, behavioral processes, and existential processes.

(2) The findings of the study shows that there are six common processes found in the speech, namely $43.8 \%$ of material processes, $32.3 \%$ of relational process which consists of $25.6 \% 25.6 \%$ attributive relational processes and $6.7 \%$ of identifying relational process, $11.2 \%$ of verbal process, $10.3 \%$ of mental process, $1.5 \%$ of existential processes, and $0.9 \%$ of behavioral processes; as for participants, the researcher has found $21.3 \%$ of actors, $19.5 \%$ of goal , $12 \%$ of carrier, $12 \%$ of attribute, and the rest participant roles are less than $30 \%$.

The researcher can give some suggestions for the next researchers or other people who are interested in this research that using Transitivity System for the analysis of discourse is a very interesting research topic because it reveals meaning behind a language as social practice. However in this research, the researcher only took one data source which is a political speech by Donald Trump which was delivered during one of his presidential campaign rally, at Youngstown State University, in Youngstown, Ohio, August 15th, 2016. Therefore, the next researcher can take more other sources about Donald Trump's discourse especially about ISIS in various sources, like his tweets, or status on Facebook and so on to find out the Donald Trump's ideology on ISIS in general.

\section{REFERENCES}

Bogdan, R, And Biklen, S.K. 1992. Qualitative Research For Education: An Introduction To Theory And Methods. Boston: Allyn And Bacon.

Gerot, L And Wignell, P. 1992. Making Sense Of Functional Grammar. Australia: Gerd Stabler.

Halliday, M. A. K. 1978. Language As Social Semiotic: The Social Interpretation Of Language And Meaning. Baltimore, Md: University Park Press.

Halliday, M. A. K.1985. An Introduction To Functional Grammar. London: Arnold .

Halliday, M.A.K. 1994. An Introduction To Functional Grammar. 2nd Edition. London: Edward Arnold.

Schriffin, D., Tannen, D., \& Hamilton, H.E. 2001. The Handbook Of Discourse Analysis. Great Britain: Blackwell Publishers. 